\title{
Environmental Impact Statement
}

THE

GRIZZLY BEAR

IN

NORTHWESTERN MONTANA

\section{SUMMARY}

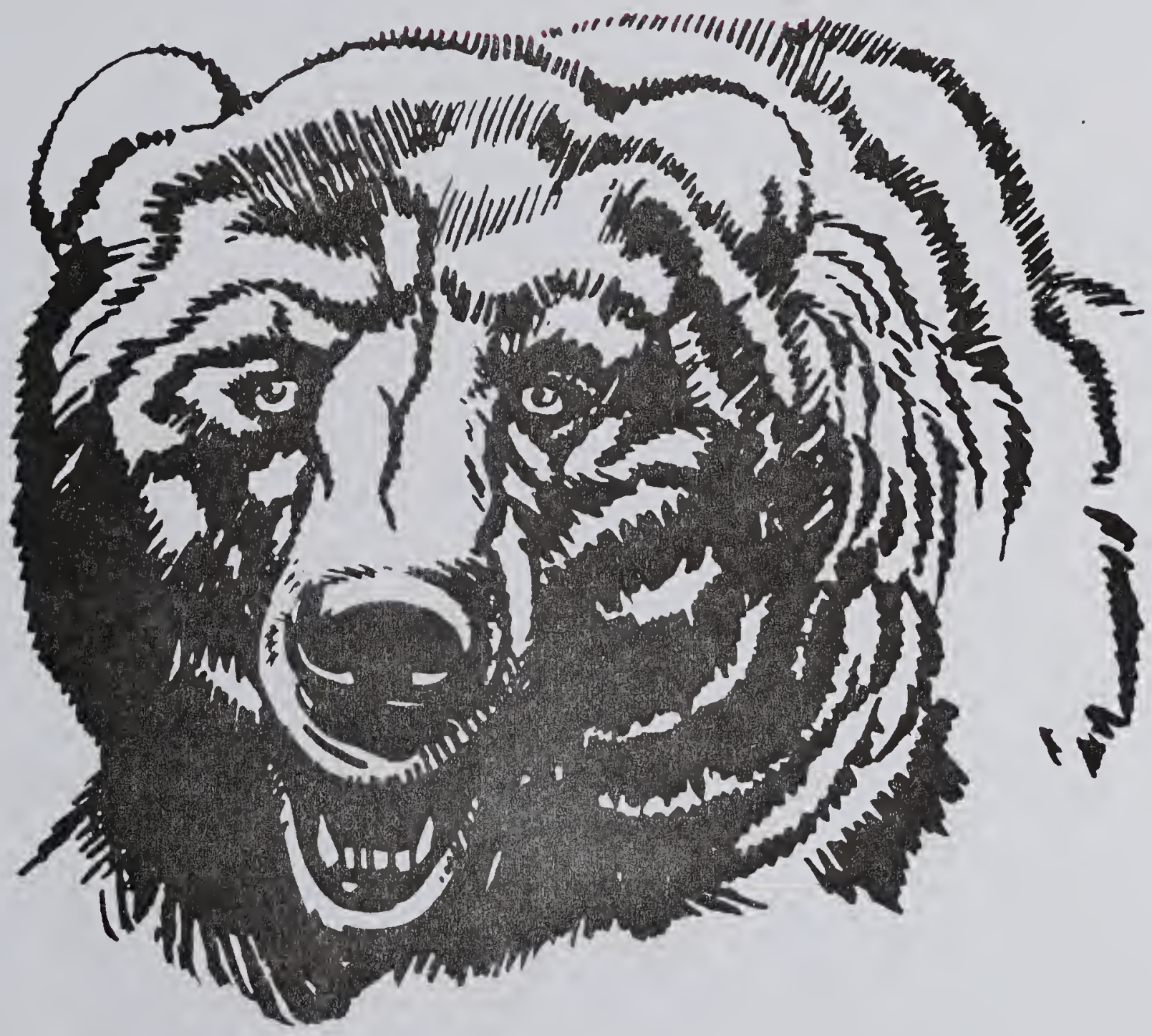

Montana Department of

Fish, Whillife Q $\&$ Parks

1420 East Sixth Avenue

Helena, Montana 59620 


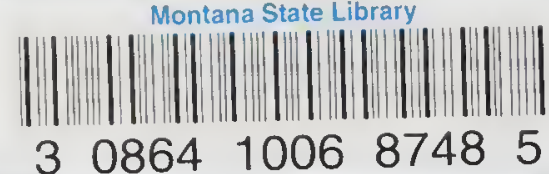




\section{SUMMARY}

\section{EINAL PROGRAMMATIC ENVIRONMENTAL IMPACT STATEMENT THE GRIZZLY BEAR IN NORTHWESTERN MONTANA}

Montana Department of Fish, Wildife and Parks

Primary Authors:

Arnold R. Dood

Robert D. Brannon

Richard D. Mace

March 1986 
0

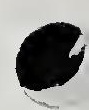

0 
Grizzly bear management in Montana was addressed within the framework of MEPA and its regulations. This programmatic review concerns that portion of Montana known as the "Northern Continental Divide Ecosystem" (NCDE) and the "Cabinet-Yaak Ecosystem" (CYF).

Montana contains all or portions of four of the six areas identified as occupied by grizzly bears in the Grizzly Bear Recovery Plan (USDI 1982). Of these four, only the NCDE and CYE contain enough grizzly habitat within the state to allow for the Department program, by itself, to significantly guide the management of grizzly bear. Although Montana's management program influences grizzly management in other areas ( 1 ike the Yellowstone), management in those areas requires a joint effort with adjacent states.

This document, therefore, describes on 1 y the Department's program as it pertains to areas in and adjacent to the NCDE and CYE in Montana. The management directions for the Selway-Bitterroot and Yellowstone grizzly bear ecosystems are not included.

This summary presents the Department's objectives for grizzly bear management in northwestern Montana, a review of population status in the CYE and NCDE, the Department's preferred alternative, the environmental impacts of this alternative, the Department's other recommendations for management, and responses to substantive comments on the Draft EIS. References to the Final EIS are made in the text, and the reader should consult the Final for more detail on the discussion in this summary.

\section{Northern Continental Divide Ecosystem (NCDE)}

To manage for a recovered grizzly bear population and to maintain distribution in the management area as defined in Figure 1, and seek to maintain the habitat in a condition suitable to sustain the population (excluding Glacier National Park) at an average density between 1 bear/30 $\mathrm{mi}^{2}$ to 1 bear/15 $\mathrm{mi}^{2}$.

\section{NORTHERN CONTINENTAL DIVIDE ECOSYSTEM (NCDE)}

(EXCLUDING GLACIER NATIONAL PARK)

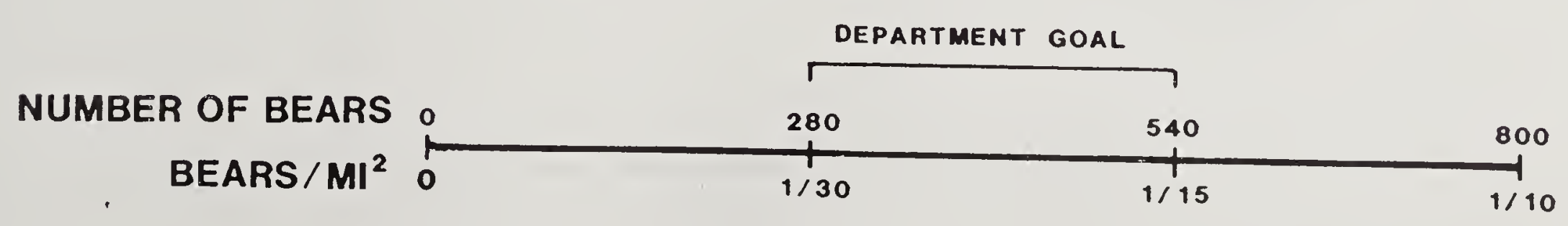


Cabinet-Yaak Ecosystem (CYE):

To manage for a recovered grizzly bear population and to maintain distribution in the managent area as defined in Figure 2, and seek to maintain the habitat in a condition suitable to sustain the population at an average density of 1 bear/40 $\mathrm{mi}^{2}$ to 1 bear/30 $\mathrm{mi}^{2}$.

\section{CABINET YAAK ECOSYSTEM (CYE)}

DEPART MENT GOAL

NUMBER OF BEARS BEARS $/ M^{2}$

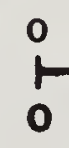

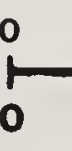

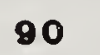

$1 / 40$
125

$1 / 30$ 


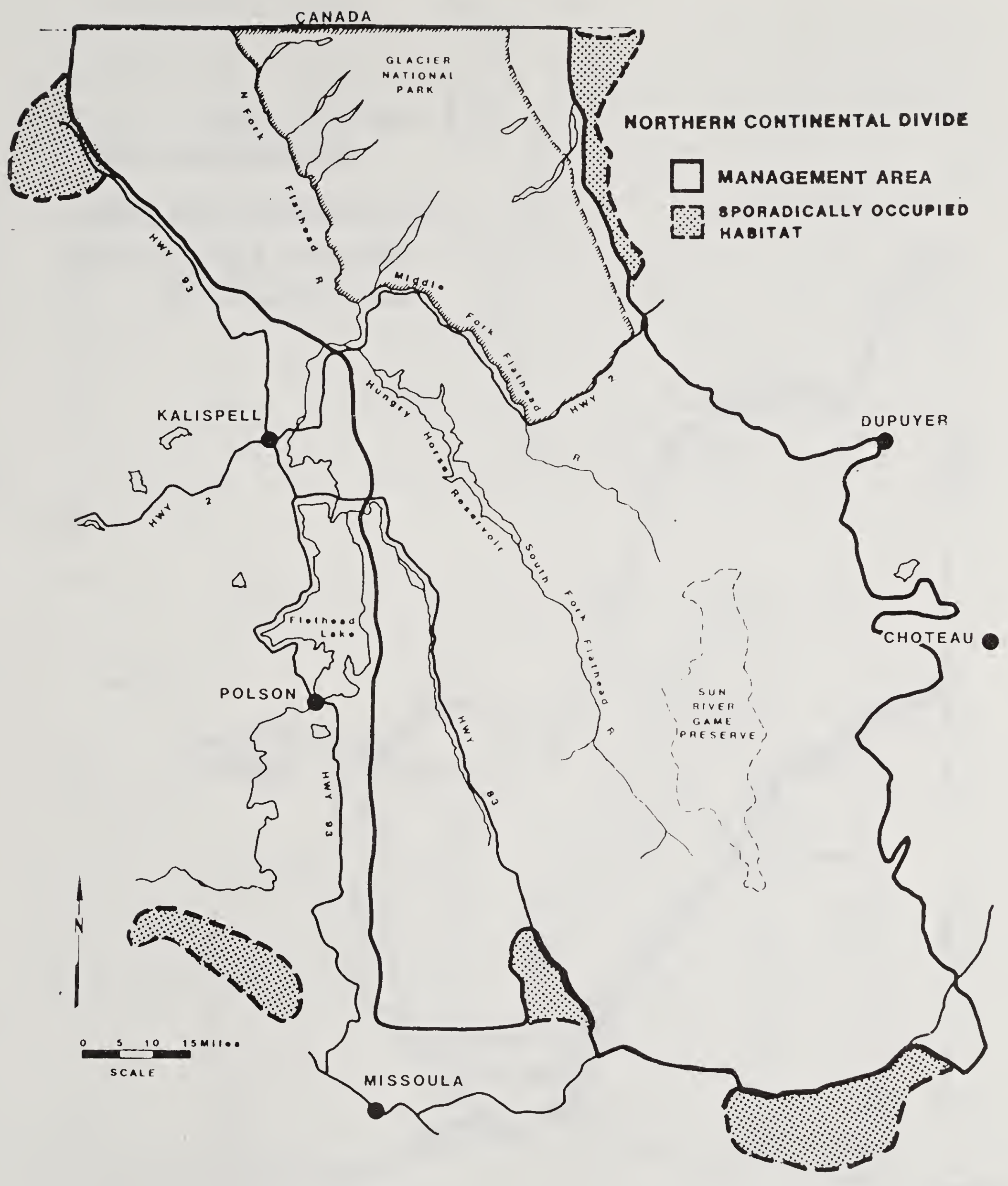

Figure 1. Grizzly bear managenent area in the NCDE. 


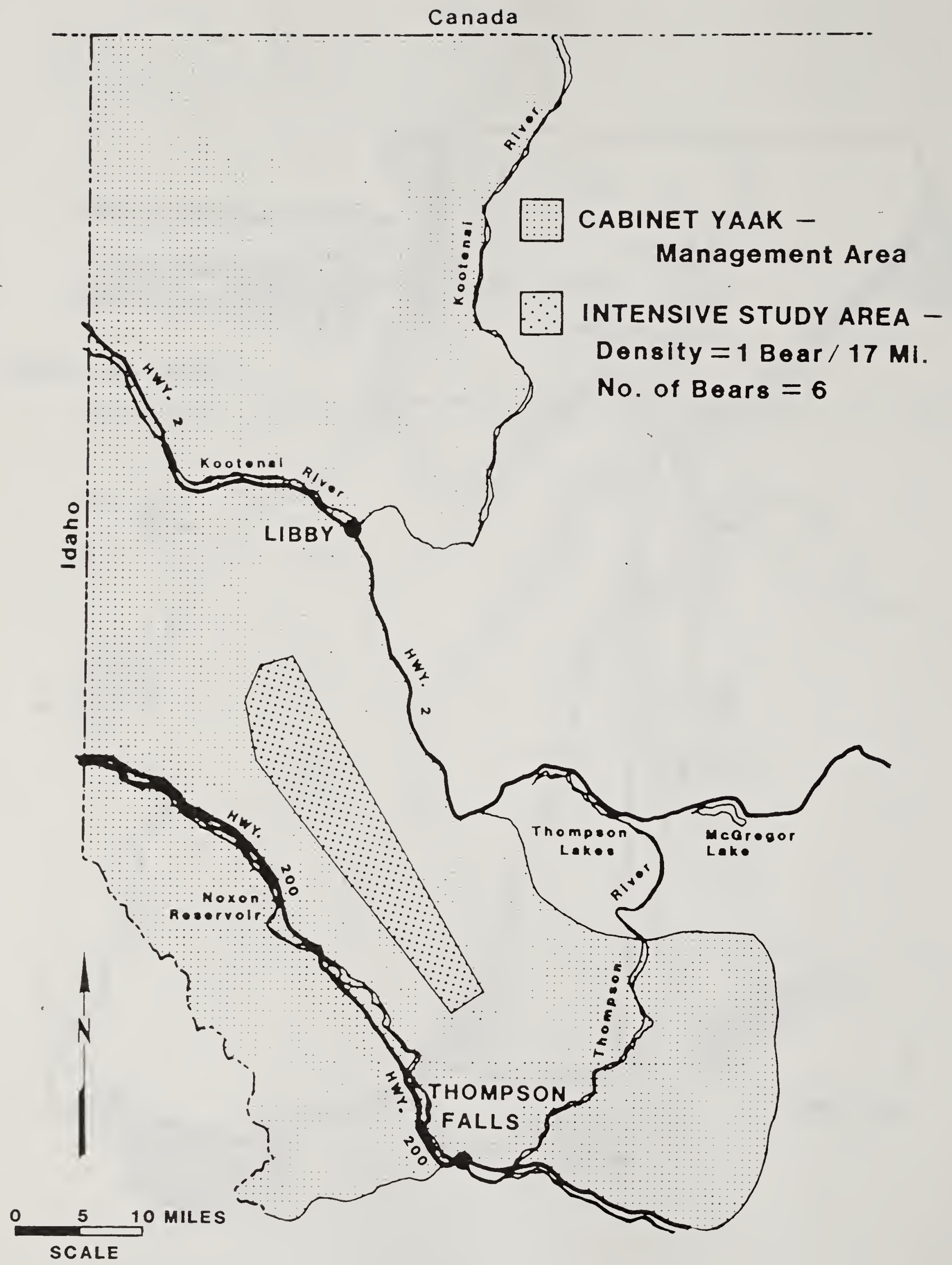

Figure 2. Grizzly bear management area for the CYE. 


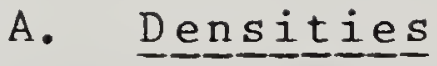

Estimated ranges of grizzly bear densities ( $\mathrm{i}^{2} / \mathrm{bear}$ ) in the NCDE for 12 units (Fig. 3) were based on similarity in habitat-use patterns, mortality patterns, home-range size and overlap, levels of human activity and encroachment, pooled expertise from professional biologists, and other factors (Appendix E). These estimates (Table 1) were developed utilizing known minimum densities from five study areas (Table 2, Fig. 3) within and adjacent to the ecosystem and applying them to larger areas. Reynolds and Hechtel (1980) reported that extrapolations of bear densities from areas and habitats of intensive study give the best population estimates. Others (Zunino and Herrero 1972; Martinka 1974: Pearson 1975; Lortie 1978; Miller and Ballard 1982; Tompa 1984; van Drimmelen 1984) estimate population numbers using data extrapolated from intensive study areas. This procedure is widely used for other species (Schemnitz 1980). In areas where direct extrapolation was judged to be inappropriate based on habitat, human impacts, and pooled expertise of other professionals, we applied a lower conservative density.

Table 1. Grizzly bear density estimates for the NCDE.

\begin{tabular}{|c|c|c|c|c|c|c|}
\hline \multirow[t]{2}{*}{ UNIT } & \multirow[t]{2}{*}{$\begin{array}{l}\text { AREA } \\
\left(m i .{ }^{2}\right)\end{array}$} & \multicolumn{3}{|c|}{$\begin{array}{c}\text { DENSITY } \\
\text { (mi. } 2 \text { /bear) }\end{array}$} & \multicolumn{2}{|c|}{ NUMBER } \\
\hline & & $\overline{M i n} . \bar{a}$ & Low & $\mathrm{Hig}$ & L OW & $\mathrm{High}$ \\
\hline Glacier National Park & $15 \overline{3}$ & $\overline{8}$ & 8 & $\overline{6}$ & $1 \overline{9} \overline{3}$ & $\overline{2} \overline{6}$ \\
\hline Red Meadow & 215 & -- & 15 & 10 & 14 & 22 \\
\hline Whitefish & 831 & -- & 25 & 18 & 33 & 46 \\
\hline St. Mary & 211 & -- & 20 & 10 & 11 & 21 \\
\hline Badger-Two Medicine & 323 & -- & 20 & 16 & 16 & 20 \\
\hline Swan Front & 780 & -- & 30 & 20 & 26 & 39 \\
\hline South Fork & 1624 & 19 & 15 & 10 & 108 & 160 \\
\hline East Front & 1119 & 22 & 18 & 12 & 62 & 93 \\
\hline Mission Mountains & 1044 & 56 & 45 & 25 & 23 & 42 \\
\hline Scapegoat & 1903 & 28 & 30 & 18 & 63 & 106 \\
\hline & -- & & -- & - & --- & $\ldots$ \\
\hline TOTALS & 9633 & & 18 & 12 & 549 & 813 \\
\hline TOTAL & 8050 & & 23 & 15 & 356 & 549 \\
\hline
\end{tabular}

(excluding Glacier

Nationa1 Park)

These densities are those reportedin the literature or from re-evaluated data from research studies (Appendix E). 


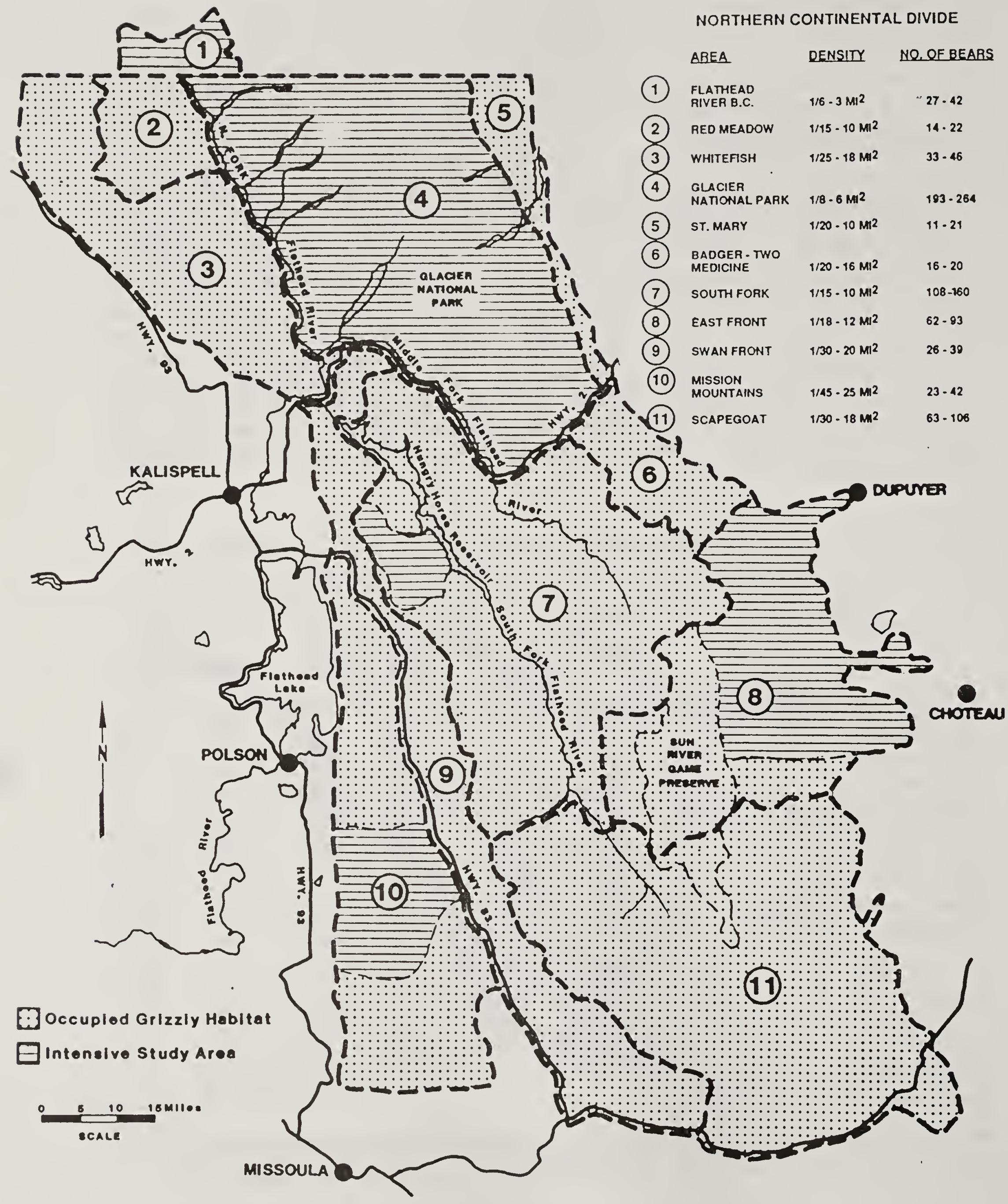

Figure 3. Grizzly bear density estimates in the NCDE. 
Table 2. Grizzly bear density estimates from study areas in and adjacent to the NCDE.

$$
\text { UNIT }
$$

$$
\begin{array}{cc}
\text { AREA } & \text { DENSITY } \\
\left(\mathrm{mi}^{2}\right) & \left(\mathrm{mi}{ }^{2} / \text { bear }\right)
\end{array}
$$

NUMBER

$\begin{array}{lccc}\begin{array}{l}\text { Glacier National Park } \\ \text { (Martinka 1974) }\end{array} & 1583 & 8 & 193 \\ \begin{array}{l}\text { Rocky Mtn. East Front } \\ \text { (Aune et a1. 1984) }\end{array} & 689 & 11.5-22.2 & 31-60 \\ \begin{array}{l}\text { Mission Mtns. } \\ \text { (Servheen 1981) }\end{array} & 301 & 19 & 16 \\ \begin{array}{l}\text { South Fork } \\ \text { (Mace and Jonke1 1980) }\end{array} & 128 & 10 & 13 \\ \begin{array}{l}\text { Elathead River, } \\ \text { British Co1umbia } \\ \text { (McCle11an 1984) }\end{array} & 163 & 3.4-6.0 & 27-42 \\ \end{array}$

Kasworm (1985) estimated a density of $1 / 17 \mathrm{mi}^{2}$ for a smal1 study area (Fig. 2) in the Montana portion of the CYE. However. sufficient information is not available to allow extrapolating this density to a larger area.

\section{B. Population Status}

Our current estimate of the minimum population for the NCDE, based on the density estimates discussed earlier, is 549. Excluding Glacier Nationa1 Park, the number is 356 grizzly bears. The G1acier National Park segment of this population has remained relatively stable at an average of 201 from 1967-1981 (Martinka 1982). Martinka (1982) further stated that the population in a region encompassing most of the NCDE was viable and near the level of 500 proposed by Franklin (1980) as necessary for maintaining genetic variance. Shaffer (1983) reported that the minimum viable population size for the rellowstone ecosystem was 50-90 grizz1y bears.

Although methods used in deriving the population estimates varied, it is possible to compare historical grizzly bear population estimates. Cooney (1941) estimated 112 grizzly bears in a portion of the Flathead and Lewis and Clark national forests. This estimate was based on miles of trail traveled per bear or bear sign observed. Cahalane (1952) reported an estimated $120 \mathrm{grizz} 1 \mathrm{y}$ bears in Glacier National Park in 1951. Based on the best information available, Hickie (1952) reported an estimate of 758 grizzly 
bears in a11 of Montana. Cooney (1953) reported a 1953 population estimate of 800 in Montana. Marsha11 (1955) reported an estimate of $700 \mathrm{grizz} 1 \mathrm{y}$ bears for the entire state in 1954. He considered the harvest of 39 (5.6\%) not to be excessive given the population estimate. Montana 1isted 439 grizzlies in 1955 in its population exclusive of nationa 1 parks (Cooney 1956). Cooney (1956) a1so reported 100 for Glacier National Park. Ham 1in and Frisina (1975) reported, based on a survey of professionals and user groups, that the grizzly population in Montana was at least stable and possibly increasing.

Several researchers have pointed out the difficulties of trying to estimate grizzly bear populations (Martinka 1974; Quimby 1974; Pearson 1975; Craighead et a1. 1976; Reynolds and Hechte1 1980; Meagher and Phillips 1983). A1though this information is valuable and should be obtained where feasible, precise estimates of grizzly bear populations are not required for management (Reynolds and Hechtel 1980 ; Archibald 1983; Johnson 1980). Further, to expect that carrying capacity can be determined at present, is unrealistic. Meagher and Phillips (1983) reported that the carrying capacity could not be determined for a population in Yellowstone that had been studied for 24 years.

Comparing historical information with our present estimates indicates the current grizzly bear population in Montana is as high or higher than that reported 30-40 years ago. It appears that factors such as acquisition of some key habitats, implementation of more conservative control programs, restrictions on hunting, and controls on predator poisoning have a 11 owed growth in Montana's grizzly bear populations. This growth has occurred in spite of habitat encroachment.

It should be noted that there are problem areas within the ecosystems. Aune (pers. comm.) indicates that the Badger-Two Medicine area is a high-mortality area. Claar et a1. (In Press) stated that the population segment in the Mission Mountains is declining. These problem areas will need special management attention.

A survey of our Department's biologists and wardens and our state's licensed outfitters was conducted to determine their assessment of the current trend of the grizzly bear population in Montana as well as its distribution. These surveys were designed simply to assess these groups' opinions. It was not meant to represent the state of the art in survey design, nor was it designed to be evaluated statistically. As discussed in the EIS, this technique will be designed to provide for statistical evaluation if it is to be used in the future.

These informal surveys indicated that the distribution and status of grizz1y bears in the NCDE is stable to 
increasing. The results for the CYE indicated the population and distribution are likely stable to decreasing. This supports the contention that a strong recovery effort is necessary for the CYE population.

It is difficult to use age data from hunter harvest to describe population status (Harris 1984a). This difficulty is a result of two possible but opposite interpretations of harvest age data. First, declining mean or median age of harvested bears over time may indicate that either the majority of older age animals have been harvested (i.e. overharvest) leaving mostly young animals to be harvested, or that underharvest has allowed the young age classes to increase. Secondly, increasing age in the harvest may indicate that underharvest is allowing increased survival and an increase in older age classes, or that overharvest has removed the majority of young age classes, 1 eaving on 1 y older age c1asses for harvest (G1enn 1975, Swenson 1985, Bunnel1 and Tait 1985, Kolenosky In Press). It is important, therefore, that when using harvest age data to interpret population status, it should be considered in conjunction with other population and trend indicators.

Population modeling efforts using mortality data for the NCDE have been conducted by Klaver (pers. comm., Bureau of Indian Affairs, Pab1o, MT) and Harris (1984a). Both models were updated using the most current mortality data of Greer (1985). Both Klaver and Harris have aptly demonstrated the problems encountered when using sex and age data from mortality records. They have demonstrated the need for a measure of hunter effort.

Harris (1984a) examined age and sex structure from simulated grizzly populations subjected to various harvest levels. He devised a statistical procedure based on harvest data to test the nul1 hypothesis of overharvest, but concluded that the test was insensitive (power estimated to be less than 50\%). When applied to 1970-1981 grizzly bear data from the NCDE, grouped by three-year blocks, the test was unable to reject the null hypothesis of overharvest at the $90 \%$ confidence leve1. However, when applied to 1982-1984 harvest data, the index indicated a $10 \%$ or 1 ess chance the population (for this time block) was declining (Harris pers. comm., University of Montana, Missoula).

K1aver has modeled the 1970-1984 mortality data for the NCDE using the traditional methods of Gilbert et a1. (1978) and a simplified approach to the Fraser et a1. (1982) method. This analysis shows that harvest rates have been declining in recent years and that population indices indicate a stable or increasing population (Klaver pers. comm.)

Population trend information is available for three intensive study areas within or adjacent to the NCDE. The portions of the ecosystem in the RMEF (Aune, pers.comm.) 
and the British Columbia portion of the North Fork of the Flathead River (McLe11an 1984) are both stable to increasing. Grizzly bear numbers in the Mission Mountains are reported to be declining (Claar et al. In Press).

A task force appointed by the Interagency Grizz1y Bear Committee met in 1984 in an effort to determine population size and trends in the NCDE. Their executive summary stated. "The available population data did not permit the task force to estimate total numbers of bears, to detect any significant trend or even to confirm population stability in the grizzly bear population of the Northern Continental Divide Ecosystem". However, they stated in the same summary, "While we are unable to eliminate the possibility of slow, long-term trends, we found no indication that current management threatens the population in this region" (emphasis added).

Our review of the population and trend information also failed to show any indication of a general decline in the NCDE population. In fact, there are indications that the population is stable or increasing.

Kasworm (1985) stated that there were 15 observations of females with young reported since 1975 in the CYE and that 8 of these have occurred since 1980. He also developed a density estimate using the composite home range of 2 radiocol1ared bears and including a differentiation of track measurements which yielded 4 additional grizzlies. However, he indicated that this estimate could not be extrapolated to the entire ecosystem to estimate population size. This information and the results of the informal surveys discussed earlier indicate that the population in the CYE is stable to decreasing.

\section{PREFERED ALTERNATIVE}

The management program preferred by the Department is the hunting alternative (A1ternative 2). This is the preferred alternative for both the NCDE and the CYE. However, the difference in population status in the two ecosystems demands a different management option for each. The preceding portions of this EIS indicate that the present status of the NCDE is stable to increasing at an estimated minimum of 356 (excluding Glacier National Park). This indicates that a regulated hunting season under Population Status C (Fig. 4) should be recommended. Further, the Department recommends that this hunting season be conducted under a total mortality quota and a female mortality subquota, both of which would apply only to the NCDE. A hunting season is recommended for the following reasons:

1. An average of 10 grizzly bears are legally harvested annully in the NCDE. There is no evidence in the 


\section{NORTHERN CONTINENTAL DIVIDE ECOSYSTEM (NCDE)}

(BASED ON MINIMUM DENSITY EXCLUDING GLACIER NATIONAL PARK)

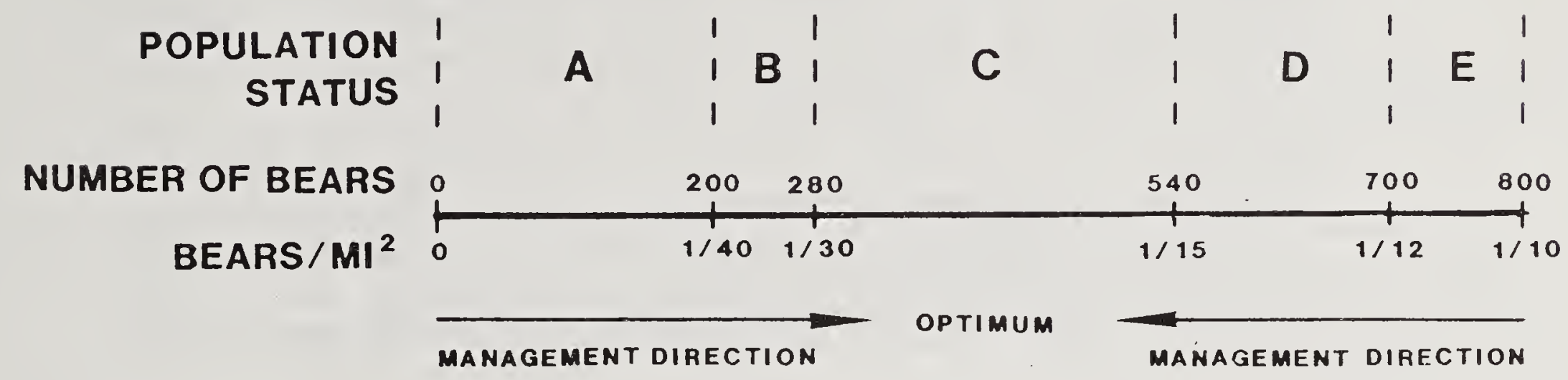

CABINET YAAK ECOSYSTEM (CYE)

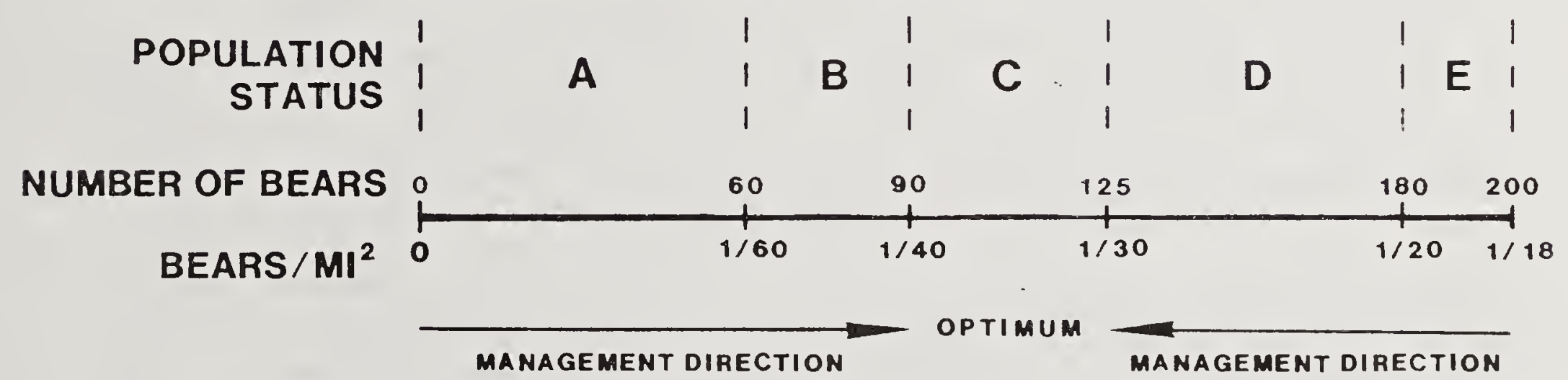

Figure 4. Management direction by population status in the NCDE and CYE. 
population structure or population trend data to suggest this 1 evel of 1 ega 1 harvest is detrimental to the population.

2. Hunters might legal1y harvest problem bears and bear/human conflicts could be reduced through such harvest.

3. Hunting may reduce the need for agency control of problem bears. Troyer (1961), Greer (1976b), Mysterud (1980), Poelker and Parsons (1980), and Waddel1 and Brown (1984) a11 indicated that hunting can reduce the need for control actions.

4. Hunting may cause bears to be wary of humans. Evidence is provided by Mysterud (1977) and Elgmork (1978) who reported wariness in brown bear populations long exposed to human exploitation. Herrero (1985) provides evidence that bear/human incidents are more frequent in unhunted than hunted bear popu1ations.

5. Hunting grizzlies may increase cub survival and recruitment providing for population increase ( indzey et a1. 1983, Inukai 1972, Young and Ruff 1982, Troyer and Hensel 1964, Glenn et a1. 1976, Pearson 1976, Reynolds and Hechtel 1980, Stringham 1983 ).

The status in the CYE indicates that the recommended management action there should be listed under Population Status A (Eig. 4)(i.e. grizzly hunting season closeded).

The Department recommends that Euture management actions in each ecosystem be based on the status of each of the populations as determined by reviewing the following criteria. It should be recognized that population status will be determined not by any one of these criteria, rather, a collection of the best available information from these criteria will be used. Very few of these criteria allow for determination of population status in the short term (i.e. 1-5 years). They are more appropriate for determination of 1 ong term (i.e. 10 years) changes in status.

A. Criteria for Deterininjng Management Directition.

Several important factors have been iclentified in this EIS that will be evaluated by the Department when determining population status. These criteria and a brief description of each are given below.

1. Federa1 Restrictions: Federal. laws and regulations may have major influence on Department regulations. Specifically, the Endangered Species Act, the Code 
of Federal Regulations, and the Grizzly Bear Recovery Plan will be consulted.

2. Resu1ts of population trend surveys: A systematic method to survey public and professional sectors will be developed. Results of the most recent survey will be consulted.

3. Professional opinions will be gathered at an annual meeting.

4. Public opinions and perceptions from annual tentative season meetings will be solicited and eva 1 uated.

5. Results of population and habitat research will be consulted. Specific changes in age structure, unreported mortality from marked bears, population densities, habitat use, and habitat quality will be considered.

6. Major changes in human use of management areas will be evaluated. Because Montana's grizzly bears are linked to those in Canada, Canadian land-use changes will be monitored as we11.

7. Changes in the population status in Canada and U.S. and Canadian parks will be gathered through discussions with the appropriate management agency.

8. Changes in state and federal road closure policies will be evaluated because they influence the number of grizzly bears susceptible to mortality.

9. The realized or perceived changes in the price of grizz1y bear parts will be evaluated. Such changes may affect the level of profiteering.

10. An attempt will be made to document grizzly bear range expansions or contractions through data gathering. This data will help evaluate changes in the population status.

11. Based on a 11 available evidence, changes in management areas or management unit boundaries will be evaluated.

12. The number of control actions will be determined annua $11 y$. If a trend is apparent in 4 or 5 years of analysis, then the program will be re-evaluated. The number of transplants from or into the ecosystems wil1 be documented.

13. Grizzly bear management policies in Glacier National Park, the Flathead Indian Reservation, and the 
B lackfeet Indian Reservation will be evaluated in relation to Department policies.

14. As further information is accumulated on transplant success, the opportunities and limitations of the technique will be evaluated. Scrutiny of population augmentation as an effective management tool will also be conducted.

15. Evaluation of mortality statistics will be conducted. The following mortality statistics are of particular importance:

a. Male/female sex ratio.

b. Median age of harvest: median ages should be calculated separately for males and females.

c. Determine total mortality: trends in total number of bears should be evaluated in conjunction with other population statistics to determine if changes in mortality quotas are needed.

16. Monitor 1itter sizes: 1itter sizes throughout the ecosystems will be recorded and evaluated annually.

17. Evaluate hunter effort: the annual hunter questionnaire recommended 1 ater in this EIS will be evaluated. Changes in hunter effort, number of shots fired, location of hunt, etc. will substantially aid interpretation of population statistics.

\section{B. Regulations}

Because the recommended management of the CYE population comes under Population status $A$, with a closed hunting season, no hunting regulations will be recommended for the CYE at this time. However, because the NCDE population is judged as being under status $C$ with the grizzly bear hunting season open, some hunting regulations should be recommended. The regulations recommended include:

1. Bag 1imit of 1 grizziy in a lifetime.

2. Prohibit the taking of young and females accompanied by young. (Young are defined as two-year-olds or younger.)

3. The grizzly bear hunting season will close on 48hours notice when the total mortality quota is reached, or it will be closed in areas where female subquotas have been met.

4. Hunters must retain the hide and head from each 
grizzly bear taken. Fvidence of sex must remain intact on the skin or carcass.

5. Prohibit all persons from removing any portion of a grizzly from the state of Montana without first purchasing a trophy 1 icense.

6. Hunters taking a grizzly bear must report the ki11 within 48 hours to an officer of the Department. Furthermore, the hunter must personally present the hide and sku11 within 10 days to an officer of the Department for inspection, tagging, and recording of ki11.

7. Adjust the total or female mortality quota annualy.

8. Request that hunters not shoot any bear in a group.

The justifications for these regulations were discussed in the EIS (see Regulations under MANAGEMENT ALTERNATIVES). It should be noted that regulations $2-8$ are already in place.

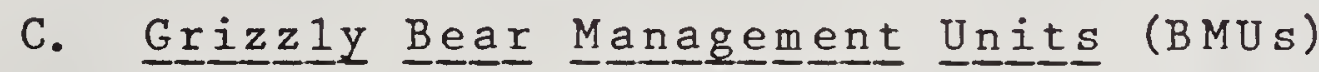

The Department prefers to treat the entire CYE as one management unit. Little population or habitat information is available to recommend any other alternative. Research currently in progress (Kasworm 1985) may provide information that would change this recommendation.

Within the NCDE the Department recommends establishing the 5 BMUs presented in Fig. 5. These will provide the areas within which the Preferred Alternative for the NCDE may be applied. If necessary, adjustments to the unit boundaries will be made as information accumulates.

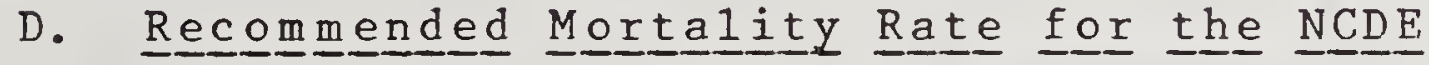

The annual known total mortality in the NCDE since 1975 has averaged 18 bears, or a rate of $5 \%$ based on the current estimate (356) of the minimum population exclusive of Glacier National Park. Estimated un rep으늘ㅇ man-caused mortality averages 7 bears a year, based on this population estimate, for a total mortality of 25 bears or $7 \%$ of our estimate of the minimum population.

In other areas, recommended or reported hunter harvest, tota 1 known man-caused, and total known man-caused and natura 1 morta 1 ity is $3-7 \%, 3-8.2 \%$, and $10.5-14.4 \%$, respective1y ( $T a b 1 e 21$ ). Hunter harvest, total known man-caused mortality, and total known man-caused and estimated unreported man-caused mortality have averaged $3 \%, 5 \%$, and $7 \%$, respectively, in the NCDE since 1975. 


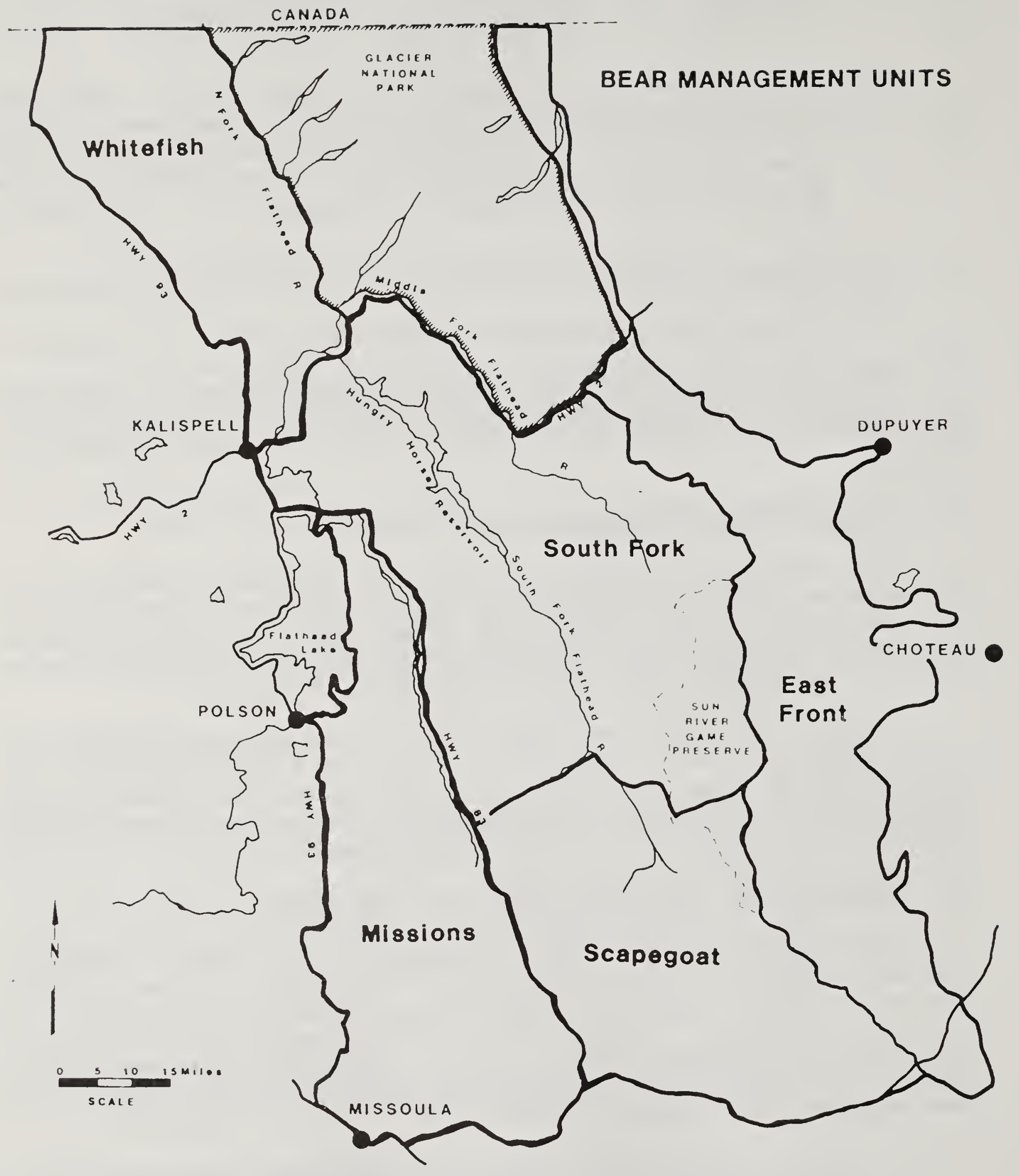

Figure 5. Grizzly bear management units divided into ecologically similar units. 
Harris (unpubljshed data) has indicated that an annual mortality rate of $6.5 \%$ is sustainable based on efforts designed to model the NCDF population. Note that this mortality rate consisted of $69 \%$ males and that harvests with higher proportions of males would allow for a higher mortality rate. Hunter harvest for 1985 in the NCDF. was $100 \%$ male. The assumptions, methods, results, and interpretations of this stochastic, density-dependent model are presented in Appendix L.

The current population status in the NCDE, the apparent trend of this population in relation to past mortality rates, and the recommended and reported mortality in the literature indicate that a proposed total man-caused mortality rate (known and unreported) of $6.0 \%$ ( 21 bears) will not be excessive for the NCDE population and should allow for a continuing increase in numbers.

Although the Department has chosen to exclude Glacier National Park from management consideration, it is important to relate the proposed mortality rate to the entire NCDE. The estimate of the minimum population for Glacier is 193 bears, thus the estimate of the minimum total population for the NCDE is 549 grizzly bears. Under the present quota a maximum of 21 deaths would be allowed from this population. Considering this Park population reduces the mortality rate to $4.0 \%$. Based on our computer simulations (see Current Management Program), a $4.0 \%$ annual mortality will allow for population growth.

Because the model presented by Harris (Appendix L) is a trackable method for determining the sustainable mortality rate for the NCDE population, the Department recommends using this model for future mortality rate determinations.

It is also recommended that the proportion of females in the total known man-caused mortality not exceed $40 \%$. This ratio is based on recommended or reported male:female ratios from 60:40 to 76:24 in the 1iterature (van Drimmelen 1984, B.C. Fish and Wildife Branch 1979; Lortie and Mchonald 1977 ; Harris (Appendix L); DeMarchi, pers. comm.), as wel1 as the past ratios in the NCDE. While it is important to keep female mortality at a minimum, and the Department is working to keep it at a minimum, it does not need to be entirely eliminated. Proposed harvest restrictions on females and relocation guidelines regarding females should reduce female mortality from that of previous years.

\section{ENVIRONMENTAL IMPACTS}

A. Irreversible and Irretrievable Resource Commitment

The level of recommended mortality, outlined in this EIS, will not result in any irreversible commitment of the 
resource. Because these levels of removal can be regulated or eliminated on an annual or even shorter time basis (should data indicate that to be prudent), the management program poses no threat to the species. In fact, more precise active management should be of benefit to the species.

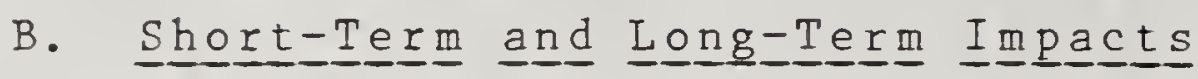

A short term impact of grizzly bear hunting is that bears will be temporarily displaced from some habitat, due to hunter activity (hunting, camping). However, the area open to hunting is large and the number of hunters is relatively $10 \mathrm{w}$. Therefore, the displacement of grizzlies by hunters will not be of much magnitude nor for more than a short time.

As human populations in grizzly habitat increase, so will the number of conflicts between man and bears. Unless human use of grizzly habitat is restricted in the shortterm, present conflicts may become chronic problems to the detriment of bears.

\section{DISCUSSION OF EXTRAORDINARY CASE}

Conservation as defined in the ESA includes the following. "and, in the extraordinary case where population pressures within a given ecosystem cannot be otherwise relieved may include regulated taking."

Because the grizzly bear is listed as a threatened species under the Endangered Species Act, the Department must demonstrate that the extraordinary case does exist before authorizing the taking of grizzly bears. Based on the review for this EIs, it is our judgement that the extraordinary case does in fact exist in the NCDE at this time. However, it is extremely important to realize that not only are biological considerations involved with the extraordinary case, but social concerns as well. Kellert (1985) stated "...attempts to consider the societal context of endangerment are typically narrow in perspective..." and "Despite the mandate of the Endangered Species Act to consider aesthetic, ecological, educational, historical, recreational, and scientific values of wildife most endangered species efforts omit consideration of these values". Grizzly bears are extraordinary in that they do come into direct conflict with people (i.e. they dokill people and livestock). Therefore, it would be inappropriate to manage them in the same way, as for example, a peregrine falcon (also 1 isted under the ESA), or under the same definition of extraordinary case applied to other species under the ESA. People will tolerate falcons in close proximity (in fact they nest on sky scrapers). However, the same cannot be said for grizzly bears. Most people are very 
uncomfortable in close proximity to grizzly bears, or become very antagonistic where livestock depredation occurs. It is this underlying social difference that dictates different management strategies for different species listed under the ESA. A program which utilizes the best available biological and social information, allows for the species to exist into the foreseeable future, allows for a continuing increase in numbers, and is designed to achieve recovery goals, does in fact meet the requirement of the Endangered Species Act and the test of the extraordinary case. With these thoughts in mind, some of the important specifics are addressed below:

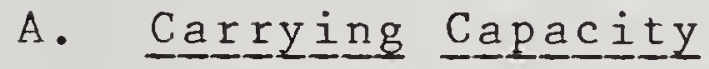

It has been suggested that to demonstrate that the NCDE is experiencing excessive population pressure it is necessary to document that the carrying capacity of the land has been met or exceeded. Ecological carrying capacity is a theoretical concept that has not been clearly demonstrated for any wildife population (Moen 1973). To measure ecological carrying capacity requires extensive data on the bioenergetics of all age and sex classes (e.g. Kcal expended per day) and an indepth measurement of habitat quaiity (e.g. Kcal available in the environment). In an area as large and rugged as the NCDE and with an animal as elusive as the grizzly bear, it is not possible in the foreseeable future to measure ecological carrying capacity with any reasonable accuracy. Picton (1983) has developed an index to ecological carrying capacity utilizing climate. However, it does not include human influences. Obviously, humans are part of the NCDF and influence carrying capacity.

There is some indication that a population slightly below ecological carrying capacity may be in a better situation biologically than one at carrying capacity (Caughley 1977). A population at carrying capacity must be reduced before an optimum sustainable yield (OSY) is possible without causing a population decline (Caughley 1977). Managing a grizzly bear population for osy provides for increased productivity as well as flexibility to remove bears for control purposes, augmentation, and hunter harvest.

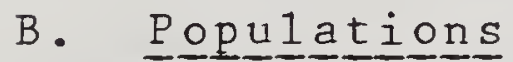

In addition to knowing carrying capacity it has been suggested that it would be necessary to precisely determine existing population numbers. Wildife management does not rely solely on precise determinations of populations but instead commonly utilizes professional judgments based on the best data available. Some critics are asking for a high level of statistical confidence on population estimates that is in fact unattainable. Although it appears that 
statistical confidence is not possible in grizzly hear research, it is possible to have reasonable confidence as managers using the approach described in Appendix E.

It does not appear that grizzly bear population pressure (or lack of pressure) can be biologica11y demonstrated at present or in the immediate future. The managenent and research tools necessary to document this are simply not available. Excessive population pressure is not clearly definied but appears to be basically a social 1 consideration,

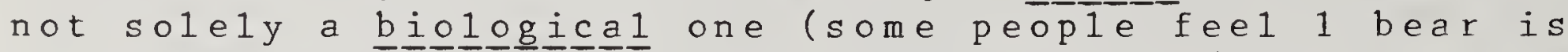
excessive while others feel 100 bears are not). Therefore, the problem is really a social one in that we must balance bear numbers with what society (especially those living with the bears) will accept, at the same time attaining recovery levels to meet the requirements of the ESA (see Public Perceptions Section IX). Newspaper articles, meetings, and individual letters have expressed concerns about grizzly bear population pressures along the East Front.

An annual increase in the number of control actions, as has occurred in parts of the NCDE, also indicates population pressure. This potential index may be confounded by an increase in the number of people occupying grizzly bear habitat. An unmeasurable change in grizzly bear behavior (e.g. habituations) may also serve to increase conflict situations without a change in bear numbers. Increased efforts in controlling conflict situations tend to mask real changes in grizzly bear population status. As long as bears and people coexist there will always be a potential for conflicts. Therefore, management flexibility is needed to successfully deal with these conflicts.

An increasing distribution of a species is also indicative of population pressures. General distribution of grizzly bears in the NCDE appears to be increasing. Bears have been observed in areas where they have not been seen for literally decades. In some instances the interpretation that this represents an increase in grizzly bear distribution could be confounded if the number of potential observers has increased or the area observed has increased.

Most of the bears that have made unusual movements have been subadult males (Aune, pers. comm.). This may indicate that population pressures in the ecosystem are such that subadults can't establish home ranges near their natal home range.

When population pressure or environmental conditions are such that bears begin to move into socially unacceptable areas (i.e. farmland and back yards) the extraordinary case applies. A limited harvest may moderate this dispersal.

The limited sport harvest applies only to a portion of the ecosystem (approximately 55\%). The remainder is closed 
to any sport harvest (Glacier National Park, Sun River Game Preserve, Mission Mountains, Blackfeet Indian Reservation, and portions of the Scapegoat and Swan Front density units).

The 1 imited harvest and regulatory changes suggested in this EIS, when implemented, will deal with the social and biological concerns for the grizzly bear. These changes include the protection of females with young, female mortality subquotas, a bag limit of one grizzly in a lifetime, adjusting the mortality quotas annually, the request not to shoot any bear in a group, and not dispatching females involved in control actions. Further, the recommendations in this EIS place the species at minimal risk and should allow for a continuing population increase.

The Department is committed to utilizing surplus bears in the NCDE to augment populations in other areas or to reintroduce this species where recovery areas have been identified. The Department is firmly committed to recovering this species.

\section{RECOMMENDATIONS}

Several recommendations are presented that should make the Department's management program more effective in the future. The Preferred Alternative presented earlier and the recommendations presented here provide a reasonable and responsive grizzly bear management program for northwestern Montana.

A. Habitat Preservation, Improvement, and L Land Acquisition

The key to the continued survival of grizzlies in Montana lies in the amount and quality of habitat which remains available to this species. Therefore, it is recommended that the Department, first, take the lead in designating areas that will be required for grizzly bear surviva 1; second, monitor changes in these habitats; third, pursue habitat acquisition, easement, and improvement in key areas: and fourth, work with federal, state, and 1 ocal agencies to preserve key habitats.

The Department supports an interagency program whose personnel would work routinely with federal land management agencies to integrate Department goals into federal programs. Although such coordination currently exists for al1 wildlife species, the Department supports an increase in priority for this program.

Identified areas of key importance are:

1. CYE (primarily along the Bull River Valley and corridors between the Yaak and Cabinet mountains).

2. Rocky Mountain East Front. 
3. North Fork of the Flathead River.

4. Swan River Valley.

5. Area between the towns of East Glacier and West Glacier along Highway 2 .

6. The Mission Front.

The Department will also encourage private conservation groups to acquire habitat and obtain conservation easements in these areas. Finally, the Department further supports some additional wilderness designations in the NCDE and CYF.

\section{B. Managagement Area Changes}

The Department recognizes that grizzly bears can and do live outside the boundary of management areas defined in this EIS. The presence of bears outside these boundaries will be encouraged as $10 \mathrm{ng}$ as conflicts with humans do not occur. If a conflict occurs, the bear responsible will be treated according to agency guidelines. If sufficient numbers of grizzlies begin to occupy land outside current management area boundaries without conflict then the Department will evaluate modifying the boundary to include the newly occupied area(s). If new areas are incorporated, the Department would seek the necessary changes from federal agencies which would allow implementing the management program. The IGBC managers subcommittee is currently evaluating recovery lines and occupied habitat 1 ines. Specific Department management procedures within and outside of these 1 ines are being developed.

\section{Intensive Research}

Research on grizzlies is difficult and requires a longterm commitment of funds. Therefore, the Department is committed to long-term ( 10 years or more) efforts in grizzly research. As long as the grizzly population in the NCDE is federal1y 1 isted as threatened the Department will need a stable funding source such as section 6 funding from the U.S. Fish and Wildife Service to conduct such work.

\section{Population Trends}

The ability to document long-term population trends is an important aspect of grizzly bear management. The Department will assist in developing and evaluating new trend monitoring techniques, including systematic subjective surveys of professionals and various user groups. Surveys should be developed by professional surveyors to ensure statistical validity.

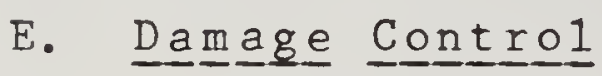

There is a need to actively deal with nuisancebears. It is therefore recommended that a minimum of 2 Department employees be trained in each region to deal with damage 
control and bear handling. Response to any grizzly bear damage complaints should be rapid. Grizzly bear complaints and conflicts must be recorded accurately. The Department a 1 so recommends that other agencies expand the area into which relocation of bears may be permitted. The Department further recommends that if aversive conditioning of grizzly bears proves effective in preventing conflicts, the technique should be adopted as a management tool.

The Department a 1 so recommends establishing a 1 imited entry damage hunt for problem grizzlies. This hunt would be conducted anytime of year a damage situation occurred. In the event of a damage situation, hunters successful in drawing a permit would be directed by Department personnel to the nuisance site for the purpose of harvesting the nuisance bear(s).

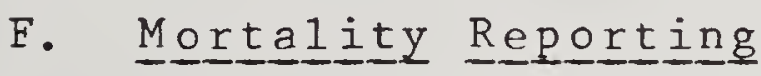

It is important that all known mortalities be reported and records maintained at one source. The Department should remain the sole mortality coordinator to which all mortalities for the state from all agencies and causes are reported. The Department further recommends that the same form (Appendix M) for recording mortalities be used by a 11 agencies.

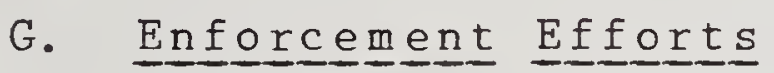

Enforcement efforts by all agencies should be concentrated in those areas with the greatest potential for problems. These areas include the Mission Mountains, Badger-Two Medicine, and the North Fork of the Flathead River. Enforcement efforts should be directed toward roaded areas in the spring and summer, and to backcountry areas during the fal1. Continued enforcement is important to keep bear parts market profiteers at a minimum. The Department recommends that a civil penalty for the illegal taking of grizzly bears be evaluated. This penalty would serve as an additional deterrent to potential poachers.

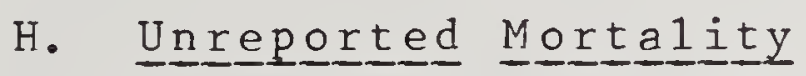

The importance of this factor dictates that this source of mortality be evaluated in the annul season setting process. Information from research projects, grizzly parts values, rumored problem areas, etc. will be reviewed in these evaluations. Major changes in the level of unreported mortality would dictate changes in the management program.

\section{Hunter $\underline{\text { Survegys }}$}

The Department recommends that all hunters obtaining a grizzly bear hunting license be surveyed on an annual basis. Information obtained from these surveys should include 
primarily hunter effort but also the number of bears or bear sign observed, dates hunted, areas hunted, hunter comments on regulations and seasons, etc. Evaluation of these surveys will substantially aid in setting seasons and interpreting population data.

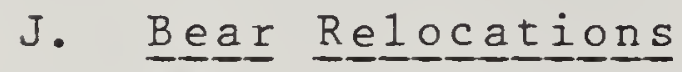

A11 relocated grizzly bears should be collared and monitored for 2 years to determine transplant success. A thorough review of this technique will improve our understanding of its viability. The U.S. Fish and Wildife Service should support this effort until all grizzly bear populations are recovered.

It is important that al 1 nuisance complaints, relocations, and other contro actions be reported and records maintained at one source. The Department should be the coordinator to which all such actions by any agency and for any cause are reported. Further, the Department recommends that all agencies use the same form (Appendix $N$ ) for recording such actions.

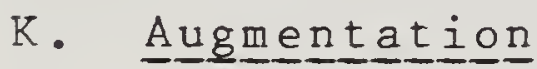

Two approaches to population augmentation are available. The first involves the transplanting of individuals from areas with a population surplus. In the past, transplants have proven unsuccessful largely because they have involved problem bears (Brannon et al. In Prep., Thier and Sizemore 1981, Cole 1976, Craighead and Craighead 1976). To increase success, transplants should involve bears in particular sex and age groups that have no history of conflicts (i.e. not nuisance bears) and are from remote areas. One possibility is to transplant bears from adjacent British Columbia into the CYE. The Department intends to work toward a cooperative agreement with the British Columbia Fish and Wildife Branch to facilitate such an exchange. With less development in the grizzly bear's range in British Columbia, bears from there would have had less contact with humans. Also, the habitat there is more like that in the CYE. Therefore, they may be less likely to cause nuisances where transplanted. In addition, the further a bear is moved from its original capture site, the more likely is the success of the transplant.

A second approach involves cross-fostering of grizzly cubs with black bear sows. Grizzly cubs, obtained either from areas with a population surplus or from zoos, could be placed in the maternal dens of black bear females in March or April. Other approaches for this technique are also available (A1t and Beecham 1984, A1t 1984). Successful fostering of orphaned black bear cubs to surrogate black bear females has been reported (Alt and Beecham 1984, Alt 1984). 
The Department recommends that augmentation, through the use of transplanting or cross-fostering, be initiated in other identified ecosystems on an experimental basis to determine its efficacy. In doing so, bears should be radioinstrumented and monitored for an extended period. Bears removed from an ecosystem for augmentation would be subtracted from that ecosystem's annual mortality quota. Augmentation will require close coordination with land managent agencies and extensive public review before implementation. If it is determined to be unsuccessful, more extreme measures will be required to recover populations in other ecosystems.

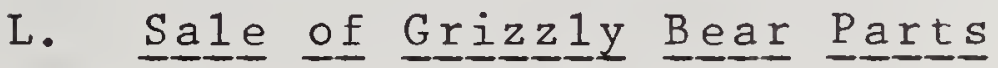

The Department should have the option of selling grizzly bear hides at public auction. This action is currently prevented by Federal regulation. Hides are obtained each year from bears lost to control actions, illegal mortality, accidents, etc. By selling these hides when appropriate (after the educational and scientific needs are met), the illegal market could be reduced.

\section{Fires from Natura1 Causes}

The Department will encourage land management agencies to allow fires to burn in wilderness and other appropriate areas within our management areas to maintain or improve the habitat to a condition best suited for grizzly bears.

\section{N. Legal Management Boundaries}

There is a clear need to modify the boundary, established in the Federal Register, within which the Department may conduct grizzly bear hunting (i.e. Flathead National Forest, Bob Marsha11, and Mission Mountains Wilderness Areas). The Department requires flexibility to implement seasons when and where appropriate within and adjacent to the present boundary. It is therefore recommended that the Department petition the USFWS to change these boundary restrictions to conform with the management areas defined in this EIS and that the mortality quota apply on 1 y to the area within this boundary.

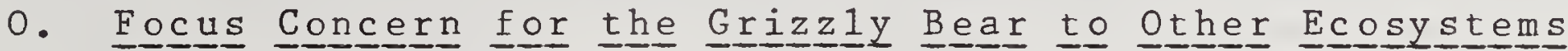

It is the Department's position that an effort be made to focus concern for the grizzly to other ecosystems identified in the grizzly bear recovery plan. To accomplish this will require the cooperation of all agencies dealing with grizzly bear management as well as the public. The Department feels this is important because biologically the grizzlies in the NCDE are least vulnerable due to the size of the current population and its proximity to the rest of the population in Canada. In addition, the status of bear 
habitat is much more secure in the NCDE due to the 1 and already established as National Park and wilderness.

The same situation is not true of other ecosystems or bears in those areas. Populations in other areas are much lower and tend to be more isolated from areas with a healthy population. Suitable habitat is much less secure in these ecosystems.

\section{P. Management P1ans by Area}

In order to improve the management of grizzly bears management plans will be developed by the Department for each of the bear management units (BMU) established under the preferred alternative. These management plans will identify specific problems and problem areas on a $10 c a 1$ level and develop strategies to deal with them. In this way the program for the ecosystem can be more responsive to changing local conditions and needs while still maintaining the overall direction recommended in this EIS.

These plans should address such things as land ownership patterns within the area, percentage of the area which is roaded, general habitat maps, problem areas, management zones for dealing with conflict situations, density goals, and 1 ocal enforcement problem areas. These plans should then be subjected to $10 c a 1$ review and comments in order to generate support for bear management at the local level. Ultimately these plans will enable us to monitor changes in habitat and local problems more efficiently.

Recent management of the grizzly bear has been falling solely on the hands of researchers. It is important that management activities be conducted by both management and research personnel and that this shift be made for the benefit of the grizzly bear.

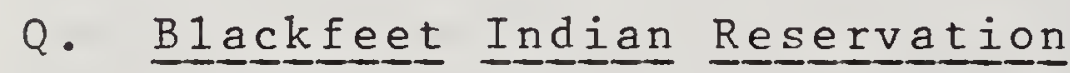

The Blackfeet Indian Reservation represents a significant portion of the NCDE. The management policies of the Reservation are critical to cooperative management of the grizzly bear in the NCDE. As a result the Department encourages the Blackfeet Indians to formulate a managemt program for their Reservation. The Department further offers its full cooperation in developing such a program and would welcome such an opportunity.

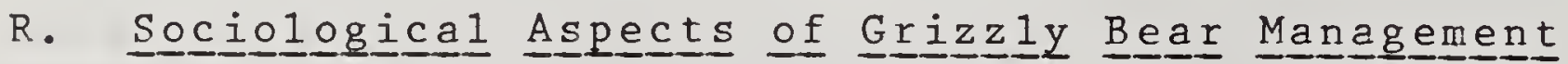

The sociology of grizzly bear management in Montana is very important to its success. Public perception, on a local as well as national level, of grizzly bear population status and of the management abilities of responsible agencies greatly influence management programs. Kellert 
(1985) suggested that people place different values on the preservation of endangered species and that this variation required systematic consideration in determining preservation priorities and implementing effective recovery programs. Because social concerns are such an important aspect of grizzly bear management, the Department recommends that a study be initiated by the state (funded by the USEWS as long as the grzzly is listed as threatened) to determine public perceptions on a local and national level concerning the grizzly bear and its status and management in Montana. The results of such a study will indicate what possible changes in direction would make the program more effective.

\section{S. Framework for Evaluation}

It is recommended that any new information be evaluated annual1y and incorporated into the management program. A review of the management program every 5 years should serve to incorporate new information. At these 5 year intervals indications of a change in population status for either the CYE or NCDE wil1 be evaluated to determine j.f management should be based on a different population status. Every 10 years the EIS will be completely reviewed and updated and a determination of population status in both the CYE and NCDE will be made. In this way the document will be as current as is practical and the management program based on it, as effective as possible.

The Department, after reviewing input from the public, wildlife professionals, etc., maintains the option to change this management program at any time in the future as is appropriate to better manage grizzly bears.

\section{RESPONSES TO COMMENTS ON THE DRAET EIS}

This section presents the substantive comments, both written and ora1, received on the Draft of this EIS. Included with these comments are the Department's (DFWP) response to each. Minor changes in wording or minor clarifications were handled on a case by case basis. A complete copy of a 11 comments, written and oral, is available upon request to DEWP. Appendix 0 contains a 1 ist of al1 commentors on the Draft of this EIS.

\section{A. GENERAL COMMENTS:}

A-1. COMMENT: Please credit the indispensable role of 1 ocal ranchers, farmers, and local communities.

RESPONSE: DFWP acknowledges the importance of those people living in grizzly bear habitat and credits much of the success of our management program to their support. The DFWP has and will continue to seek local input dealing with this 
management plan and the 1 ocal plans which are being developed.

A-2. COMMENT: An EIS just for Montana grizziy bears is totally premature. An EIs dealing with a11 6 ecosystems would be more appropriate.

RESPONSE: The rationale for this decision was discussed under the "Ecosystems Evaluated in this EIS" section of the EIS. Also, the EIS was prepared under MEPA which has no jurisdiction outside Montana.

A-3. COMMENT: DFWP's bias are twofold: attempting to recover the grizzly, and maintenance of hunting season.

RESPONSE: By 1 aw, DEWP is mandated to recover the grizzly bear. The use of a closely regulated sport hunt will help attain recovery. As past management has demonstrated, DFWP will not hesitate to close the grizzly hunting season if impacts from hunting dictate the need.

A-4. COMMENT: Do not prioritize the 6 ecosystems for recovery efforts. Efforts should be equal for all areas.

RESPONSE: The NCDE has the largest population of grizzly bears in the 1 ower 48, and this ecosystem is continuous with the population extending into Canada. Based on the review in this EIS it appears the NCDE population is likely recovered. DFWP feels that increased emphasis in the ecosystems with far fewer grizzlies is necessary given existing funding and personnel constraints. There are simply not enough resources to adequately address each ecosystem simultaneously. With continued emphasis on the NCDE needed programs in other areas will suffer and the opportunity to recover grizzlies in these areas will be lost.

A-5. COMMENT: The accuracy of the data and assumptions should be questioned, reexamined and monitored regularly.

RESPONSE: DFWP acknowledges this and will conduct a evaluation of the program every 5 years, and a complete reevaluation every 10 years. Also, a review of pertinent data is conducted annually prior to setting the grizzly bear hunting season. With these evaluations, our program should continue to be reasonable and responsive.

A-6. COMMENT: The grizz1y bear should not be classified as an endangered species on the East Front.

RESPONSE: The grizzly is classified as threatened, not endangered. At present, it is possible to delist one 
ecosystem at a time. The East Front is part of the NCDE and should not be treated separately from the entire population. The review in this EIS indicates that the continued classification as threatened needs to be evaluated and the possibility of delisting explored.

A-7. COMMENT: Saturation trapping is unnecessary. Handing should bekept to a minimum.

RESPONSE: DFWP agrees and states this in the "Research Program" section of the EIS. However, we will need additional effort to improve our management program in the future, and this effort will undoubtedly involve some handing of bears.

A-8. COMMENT: Support continued research efforts such as trapping and radio-collaring.

RESPONSE: DFWP does support research as stated in the "Research Program" section of EIS.

A-9. COMMENT: There is no excuse for DFWP to suggest that the attention given to the grizzly bear compromises the survival of other species.

RESPONSE: Given a limited amount of resources, allocating some funds to one species reduces the amount available for others. DFWP grizzly bear expenditures are currently about 10 times its revenue from 1 icense sales. The grizzly bear is classified only as a threatened species by the ESA yet a species classified as endangered, the wyoming toad, does not receive near the monetary allocation nationally as for grizzlies.

A-10 COMMENT: Could we supplement the food supp1y in poor years to help hold the bears away from border conflicts?

RESPONSE: The grizzly has a wide variety of foods from which to choose from, even in relatively poor years. The question then, is not to keep bears from starving, but rather to alter their movement patterns. Such a program, would be very expensive, and would not, in DFWP's view, be effective on a broad scale. Supplemental feeding may work on a local basis and its efficiency may be evaluated. Maintenance or enhancement of wilderness foraging habitats through fire is felt to be a more effective tool.

A-11 COMMENT: The EIS should make it clear that existing recovery goals for the NCDE and CYE are subject to review and revision. 
RESPONSE: The recovery plan is currently being revised and population goals may change. DFWP is involved in the review process and will seek biologically sound and measurable goals. It should be recognized that the population goals in the EIS are not "recovery" goals, and in fact the goals in the EIS are above the recovery goals. Our goals were placed above the recovery goals so that once these populations are delisted they won't be relisted as a result of normal population fluctuations. However, if new data become available which suggest the recovery goals should be adjusted then DFWP would support such a move.

A-12 COMMENT: The DEIS states that there are problem areas in need of special attention. Where and how will these questions be addressed?

RESPONSE: The EIS (see Population Status) discusses the problem areas which are in need of special attention and recommends that management plans be developed on a local basis, following the guidelines of the EIS, to address these local problems.

A-13 COMMENT: Why is there no 1 imit on the number of grizzly hunting 1 icenses sold?

RESPONSE: DFWP objectives in conducting hunting seasons on grizzly bears are to provide a maximum of opportunity with a 1 imited harvest. The "Preferred Alternative" in the EIS recommends that a grizzly bear hunting season be conducted under a quota system. This quota system, through its control on the harvest level, precludes the need to 1 imit hunter opportunity.

A-14 COMMENT: How is the season closed when total mortality is approaching the quota 1 imit?

RESPONSE: The grizzly bear hunting season is closed when the annual quota has been met, and the procedure for closing is explained in the "Season Setting Process" section of the EIS.

A-15 COMMENT: What does DFWP consider as an acceptable level for data, and isn't DFWP trying to fine tune management beyond the ability of the data to support it?

RESPONSE: DEWP has the responsibility to manage the grizzly bear in Montana regardless of the amount or quality of data available. DFWP's position is that the available data are sufficient for a reasonable management program. Nevertheless, additional data are always helpful and should be sought. As the agency with primary management 
responsibility, DFWP does not prescribe management strategies which the data will not support.

A-16 COMMENT: Delisting the bear should not be done until it can be done for all of Montana rather than by ecosystem.

RESPONSE: Delisting is not specifically addressed by this EIS. When the supporting evidence is sufficient to document the grizzly population in an ecosystem is recovered, anyone can petition the U.S.F.W.S. to delist. The evidence discussed in this EIS could be utilized to assess the status of the NCDE population, relative to the recovery levels. We did not since this was not the purpose of the EIS.

A-17 COMMENT: The EIS is tainted with a pro-hunting bias.

RESPONSE: First, hunting is a pivotal part of our management program and requires that attention be focused there. Second, the review of all available data, as presented by the EIS, supports the continuation of a grizzly bear hunting season in the NCDE as evidenced by the DFWP preferred alternative. Third, DFWP has been threatened with litigation over the hunting season by Defenders of Wildife and thus must discuss the issue thoroughly in the EIS.

A-18 COMMENT: Hunting should be stopped in Montana until recovery is met according to the Recovery Plan criteria.

RESPONSE: The Grizzly Bear Recovery Plan established a recovery goal for the NCDE of 560 bears. The population estimate in the EIS of 549 to 813 bears indicates the NCDE population is likely recovered. However, as 1 ong as the bear is 1 isted as a threatened species, the ESA provides for the taking (i.e. hunting) of threatened species in the "extraordinary case". As discussed in the EIS. DEWP considers that the "extraordinary case" exists in the NCDE. A-19 COMMENT: Please explain how the new ly expanded area of the CYE will be managed in comparison to the recovery plan lines, and how will management be coordinated with British Columbia and Idaho?

RESPONSE: It should be recognized that the management area boundary in the EIS for the CYE is not a recovery area as defined in the recovery plan. $\bar{D} \bar{F}$ P recognizes that grizzlies do and will continue to occur outside the federally designated recovery lines and is simply providing for management of those bears. DFWP does not suggest that the area within our boundaries but beyond the federally designated recovery 1 ines is required for recovery of the CYE population, only that the bear will be managed in these areas. Obtaining the DEWP population goal for the CYE will 
require the close cooperation of both British Columbia and Idaho. DFWP will actively seek that cooperation through fie1d and policy leve1 contacts. Not on 1 y will some guidelines be required to meet that goal, but provisions will be necessary to actively and rapidly deal with any conflicts which may occur as a result of attaining the population goal. DEWP is firmly committed to both requirements.

A-20 COMMENT: Why is the grizzly not in danger of extinction?

RESPONSE: The grizzly bear as a species (U도ㄴㅗㅗ a currently occupies more of its world-wide historicai range than many other species (it is main1y grizz1y range in the 10 wer 48 states that has diminished). The bear is treated as a game animal in the remainder of its range in Canada and Alaska. As a result there are management plans in place, research being conducted, and protection from unregulated and unlimited harvest is provided. This species is also managed in Europe.

A-21 COMMENT: The bears are getting out into p 1 aces they shouldn't be, how many are enough?

RESPONSE: The population goals presented for the NCDE outline how many bears DFWP will be managing for. However, DEWP recognizes that there are problems on the East Front. DFWP will be initiating a management program to help manage conflicts on the East Front. This program will include a regulated sport hunt and an aversive conditioning program. Personnel will be assigned to the East Front to deal with grizzly bear in this area. These actions will help deal with the problems currently being observed on the East Front.

A-22 COMMENT: Why should DFWP have the right to sell grizzly bear parts when a private citizen can not?

RESPONSE: A private citizen has the right to sell grizzly bear parts so 1 ong as the parts have been registered with the state. It is our judgement that selling bear parts at public auction may serve both to reduce the market for illegal sale of parts, and to provide us with a realistic measure of the value of these parts.

\section{A-23 COMMENT: How do we trace illegal parts?}

RESPONSE: We don't trace illegal parts. A law passed by the Montana Legislature in 1985 requires that anyone wishing to sell a grizzly bear part must first have registered the part with the Department. To be sold, each part must be accompanied by a registration certificate. Any part which 
has not been registered may not be bought or sold. People caught illegally selling parts will be prosecuted.

A-24 COMMENT: What is the effect of drugging on a bear's behavior?

RESPONSE: Studies of physiological and behavioral effects of drugs have concluded that there is absolutely no evidence that drugs currently being used have had negative effects on bears or caused them to behave in an abnormal fashion. We remain sensative to the concern that handiing may affect the bears and intend to 1 imit that activity as much as possible.

A-25 COMMENT: How will the state work to coordinate the activities of 1 and mangement agencies and corporate timber interests in the newly expanded zone? Will further road management and other restrictions of human activity be as important as what has been done inside of Recovery Plan 1ines? Will bears be augmented in the newly expanded management 1 ines? Will the state recommend the new 1 ines as Occupied Habitat 1 ines when the Recovery Plan is revised in $1986 ?$

RESPONSE: The State will provide input on al1 wildife species within this expanded zone through the various 1 and management planning programs underway and others as they are initiated.

Road management and other land-use recommendations will be based on all wildife needs. Recommendations as stringent as those within the recovery line will not be necessary.

Bears will not be augmented into the expanded area, but will be allowed to remain there if no conflicts occur.

The State will not recommend that Federal agencies extend the recovery area to coincide with the state's management 1 ine.

\section{B: ALTERNATIVES:}

B-1. COMMENT: There should be a preferred alternative for each bear management unit.

RESPONSE: The EIS is intended to direct DEWP's action for the CYE and NCDE grizzly bear populations. The EIS contains a recommendation that specific management plans be developed for each bear management unit on a $10 c a 1$ basis (i.e. by the administrative regions within which the units fal1). 
B-2. COMMENT: B 1 ack bear hunting must be 1 imited or curtailed in grizzly bear habitat.

RESPONSE: Known annual mortality from mistaken identity is one bear from an average of 25 mortalities annually in the NCDE. DFWP feels that this source of mortality, at its' current rate, is better treated through education than hunting regulation, particularly since these mortalities are included in the annual mortality quota. However, if modifications to the black bear season are necessary they may be implemented (see Management Alternatives in the F.IS). It is possible that reducing dominant male black bears may enhance grizzly recovery in the CYE.

B-3. COMMENT: Early fall hunt should be eliminated until most females have denned.

RESPONSE: Limited denning data for grizzly bears in the NCDF (see Distribution and Habitat Selection in the EIS) do not show any significant differences between sexes in terms of fall den entry time. However, a weekly analysis of hunter mortality (see Management Program Review in the EIS) shows that the proportion of females in the total mortality declines as the season progresses. DFWP believes, at this time, that the recommended regulations will serve to keep female mortality at a minimum without delaying the opening date until females have denned. However, adjustments to season dates can be made through the annual season setting process when the need dictates. This process is open to public comment.

B-4. COMMENT: A very conservative approach should be taken until more accurate predictions are made.

RESPONSE: Based on the analysis of population density. status, and level of mortality (including unreported mortality), DEWP has determined that the alternatives and recommended regulations are conservative. DFWP is committed to future investigations to aid in the improvement of the management program. The management program prescribed in

the EIS was designed to be conservative as well as responsive.

B-5. COMMENT: It is important that the bears that are killed should be the ones on the periphery of the ecosystem where problems occur.

RESPONSE: One purpose of a sport hunt is to help DFWP manage problem bears in high-conflict areas and reduce the incidence of conflict. If federal flexibility is given in the areas that can be hunted, DFWP will manage for a 
reduction of conflicts in the peripheral areas without jeopardizing these segments of the population. Limited data do show that these peripheral and $10 w-e l e v a t i o n$ areas are very good habitat. Overharvest of these peripheral segments may have negative effects on the population in the entire NCDE. It is also desirable to maintain opportunities for young bears to find suitable home ranges within the interior of this system.

B-6 COMMENT: DFWP goals were based on minimum viable population levels. Why didn't DEWP use maximum viable population levels?

RESPONSE: DFWP is managing for viable population levels in these ecosystems. The goals were developed and then supported using minimum viable population levels and other factors. The concepts of minimum and maximum viable population are theoretical, what is important is to manage for viable populations.

\section{AUGMENTATION:}

C-1. COMMENT: DFWP takes a weak stand on augmentation.

RESPONSE: DFWP has revised some statements on augmentation tomake positions and policies more clear (see Recommendations in the EIS).

C-2. COMMENT: Cross-fostering is premature at this time. Much more research is needed before it is carried out.

RESPONSE: The EIS contains a recommendation that augmentation, either by transplanting or cross-fostering, be conducted on an experimental basis until its efficacy is determined. We recognize that the potential exists for augmentation to be unsuccessful. Should a bear moved to the CYE become a nuisance it will be removed from the ecosystem.

C-3. COMMENT: It is very clear that transplantation may be necessary to re-establish populations in the selway Bitterroot.

RESPONSE: The EIS does not discuss the Selway Bitterroot Ecosystem. However, the DFWP is willing to cooperate in any efforts to augment other ecosystems. Such an effort will require a unified effort with the state of Idaho and appropriate Federal and private landowners. 
C-4. COMMENT: Evaluate the cost/benefits of moving bears to the CYE. Should put efforts in the Greater Yellowstone or Selway-Bitterroot Ecosystems.

RESPONSE: Such an evaluation will occur before augmentation efforts begin in any area as a part of the specific augmentation p1an.

C-5 COMMENT: Any portion of the annual mortality quota which is left for hunting should be used for augmentation purposes instead.

RESPONSE: It is the position of the DFWP to use NCDE bears for augmentation when appropriate. Bears taken for augmentation will be counted against any quotas established if the bears are removed from the ecosystem for which the quota applies.

\section{EXTRAORDINARY CASE:}

D-1. COMMENT: The goal of DFWP should not be to produce a maximum sustained yield of grizzly bears. The grizzly is not a game anima1, and should not be treated as such. We question the applicability of the maximum sustained yield concept to grizzly bears.

RESPONSE: The preferred alternative, mortality quotas and regulations outlined in the EIS were formulated to aim at an "optimum" sustained yield, not a maximum. This was misstated in the draft EIS. DFWP seeks a balance in grizzly bear numbers under existing social and ecological constraints.

The grizzly bear in Montana has been classified as a game animal since 1923, and this status has probably contributed to the fact that Montana has more grizzlies than any other state in the 1 ower 48. This designation demonstrated an early concern and provided monies for grizz1y managemen.

D-2. COMMENT: DFWP ignores the concept of carrying capacity. RESPONSE: DFWP discusses the carrying capacity theory in the EIS (see Discussion of Extraordinary Case in the EIS).

D-3. COMMENT: No sociological study was undertaken in regard to excessive population pressure. The EIS presented sociological supposition. Social pressure, a 1 though appropriate to a degree, has been over-used.

RESPONSE: DEWP makes no claim to have conducted such a study. However, public comment contained in this supplement 
do suggest that population pressure is a social issue as well as a biological one. DFWP has added a recommendation to the EIS that a sociological study be conducted on a local and national level to determine the public's perception of the grizzly bear's status in Montana and its management.

D-4. COMMENT: The point about sub-adult male distribution is speculative and actually contradicts current bear social behavior theory.

RESPONSE: Unpublished data of McLellan (pers. comm.) and Aune (pers. comm.) show that dispersal distance of subadult male bears is related to population density of adult animals in core areas.

D-5. COMMENT: I do not see how it is possible to demonstrate excessive populations for areas where there are no data.

RESPONSE: DFWP recognizes that there are portions of the NCDE for which there are few data. However, there are no isolated populations within the NCDE. Population pressures that exist apply to the entire population not to small portions of the population's range. It is important to recognize that the nature of grizzly bear research precludes acquiring data for every area simultaneously. Also, as studies are completed data from earlier studies may become outdated. The DFWP realizes these points and will formulate management programs using the best data available and professional judgement where necessary.

D-6. COMMENT: The density estimation procedure has clearly revealed that most units do not have excessive populations.

RESPONSE: DFWP does not believe that the extraordinary case must be demonstrated for each bear management or density unit. These units do not contain separate populations. DFwP believes that the whole NCDE exhibits characteristics of one population that interacts with animals in Glacier Park and Canada.

\section{E. GUIDELINES FOR OIL AND GAS EXPLORATION AND DEVELOPMENT:}

E-1. COMMENT: Grizzly bear management should be based on the Multiple Use and Sustained Yield Act.

RESPONSE: Any action taken under the Multiple Use and Sustained Yield Act must conform with the Endangered Species Act. However, it is the intent of DFWP to manage for recovery so that the grizzly can be delisted and management can revert to the Multiple Use and Sustained Yield Act. 
E-2. COMMENT: The specific grizzly bear guidelines, and the Interagency Rocky Mountain Front Management Guidelines are regulations which will prohibit oil and gas exploration and development.

RESPONSE: These are guidelines and not regulations. As such they serve to guide management decisions and are not as inflexible as regulations. These guidelines were first applied in 1982 and oil and gas activities increased from 1982 to 1984. Additionally, in the federal permitting process, under certain conditions, variation or deviation from the guidelines are allowed if legitimate reasons for them are presented in the Environmental Assessment for the specific project.

\section{F. MORTALITY RATE AND MODELING EFFORT:}

F-1. COMMENT: The 6.0\% mortality rate should include mancaused mortality in Glacier National Park.

RESPONSE: This mortality rate was developed for the minimum population estimate of 356 bears for the NCDE (excluding Glacier National Park). If the $6.0 \%$ rate were applied to the entire ecosystem, then the estimate of 193 bears in the Park would have to be added to the population estimate for the NCDE exclusive of Glacier. As a conservative measure the DFWP did not include the Park bears in the mortality rate determination. To do so would have increased the allowable harvest outside the Park. As stated in the EIS, the DFWP has no management jurisdiction within the Park.

F-2. COMMENT: Please put al1 of the models together.

RESPONSE: DEWP has revised the draft EIS to clarify the differences between models. Because of differences in assumptions and modeling procedures it is not possible to simply put the efforts together as suggested.

F-3. Comment: A female subquota of a maximum of $40 \%$ is not providing maximum protection.

RESPONSE: While it is important to keep female mortality at a minimum, and the following actions should accomplish this, it does not need to be entirely eliminated. Managing for female mortality not to exceed $40 \%$ allows the mortality of nomore than six females under current harvest recommendations. DFWP believes that that female hunting mortality. will be further reduced by the following 3 regulations: 1) Prohibit the taking of young and females accompanied by young (young are defined as two year-olds or younger), 2) request that hunters not shoot any bear in a group, 3) bag limit of one grizzly bear in a lifetime. 
F-4. COMMENT: Harris' mode1 is untested (unverified).

RESPONSE: DFWP acknowledges that this model is untested. Models are on 1 y as accurate as the data they use and are 1 imited to the ability of the model to mimic both grizzly bear populations and the very complex interactions of that population with the environment. Validation is vital aspect of any modeling effort. Such validation of the model via the recommended mortality rate will be a part of the annual mortality analysis.

A1though the use of Harris' model is recommended, it is not the only information used to establish the recommended mortality rate. Data and recommendations from, research and management in other portions of the grizzly range were also used (see Recommended Mortality Rate in the EIS).

F-5. COMMENT: DFWP fails to indicate what 1 evel of female mortality is acceptable. How does a female hunting mortality male:female ratio of 58:42 relate to total female mortality and the overall number of females in the ecosystem?

RESPONSE: The EIS does recommend that female mortality not exceed $40 \%$ of tota 1 mortality which will al1ow for a continued increase in the population. With this recommendation total mortality should be skewed toward males which may in the 1 ong term result in a greater proportion of females in the population.

F-6 COMMENT: Because Harris' mode1, which is untested, has shown that an annua 1 morta 1 ity of 25 leads to a population decline, DEWP is managing for a decline. And, the recommended mortality rate of $6.0 \%$ leaves 1 itt 1 e room for error based on Harris' model.

RESPONSE: A key point here is that Harris' model is untested (see comment $F-4$ ) and models exhibit much more sensitivity than actual populations. This model was on 1 y one of five tools used to evaluate population status. These were: 1) Harris' mode1, 2) K1aver's harvest analysis, 3) Harris' harvest analysis, 4) a survey of biologists and outfitters, and 5) information from intensive research areas. Both harvest ana 1 yses and the survey and research results indicated a stable or increasing population.

other data indicated that total mortality rates as high as $17 \%$ (see Tab1e 21) would allow for stable to increasing populations. To be conservative, DFWP chose a rate of $6.0 \%$. Furthermore, Harris' mode1 indicates that proportions of males in the harvest exceeding $69 \%$ would allow a higher sustainable rate of mortality. The hunter harvest in 1985 consisted of $100 \%$ males. 


\section{G. DENSITY ESTIMATES AND TREND:}

G-1. COMMENT: Display confidence limits for density estimates.

RESPONSE: As discussed in the EIS (see Grizzly Populations), the techniques used to develop the density estimates do not allow for calculation of confidence intervals.

G-2. COMMENT: Surveys of public opinion rarely give reliable population trends. Method used was unscientific and informal.

RESPONSE: DFWP does not advocate the use of public opinion surveys to determine trend. DFWP does suggest that a survey of professional biologists, foresters, and guides and outfitters may be of use. Such surveys, if conducted, would only be one of several techniques used to assess trend.

G-3. COMMENT: There is a absence of substantive discussion of habitat similarity or suitability concerning density extrapolations.

RESPONSE: DFWP realizes that definitive habitat studies are 1 acking for the NCDE and CYE. Judgments of habitat similarity and suitability were made from Border Grizzly Project reports, master's theses, fire history maps. precipitation zones, literature on distribution of habitat types, and judgment of professional biologists and foresters. Further habitat research may assist in more precisely defining units in the future.

G-4. COMMENT: Density estimates are not adequately documented to allow the reader to evaluate DFWP's judgement.

RESPONSE: The procedures used to develop the estimates were expanded upon in the Draft and Final EIS. They displayed the 3 methods used to judge density in the research study areas and the results of those analyses. DEWP presented figures on home ranges in the study areas to further aid the reader. Discussion of the rationale behind each density unit is provided in an appendix.

G-5. COMMENT: The search should not be for grizzly bear numbers, but how many reproducing adult females there are (for status and trend).

RESPONSE: Evaluation of the use of monitoring the number of females with cubs in Yellowstone indicates that this technique may be inaccurate. However, population trend information is needed and efforts to develop trend monitors should continue. 
G-6 COMMENT: Where are the data to document the conclusion that the grizzly bear population status is as high or higher than 30-40 years ago? Is such an effort the result of more bears or greater effort, or a combination of these and other factors?

RESPONSE: Historical estimates of the grizzly bear population in Montana are lower than our current estimate (see Population Status in the EIS). DFWP interpretation of these estimates is that the population has increased alorg with an increase in efforts to determine population size.

G-7 COMMENT: If inventories of grizz1y bears are not required for management, how will DFWP be able tomonitor natural versus man-caused mortality and its effect on population trends?

RESPONSE: Precise determinations of population numbers are not required for management. Population estimates and trend indicators, based on the best data available, allow management of any wildife species including the grizzly. Natural grizzly mortalities, by their very nature, are difficult to monitor. However, as data on this mortality source becomes available it will be incorporated into the management program.

G-8. COMMENT: Martinka (1982) stated that the population in a region encompassing most of the NCDE was viable and near the level of 500 proposed by Franklin. Has this biologist performed studies in a "region encompasing most of the NCDE"?

RESPONSE: Martinka's citation is listed in the EIS. For supporting information refer to that citation and the author.

G-9. COMMENT: Does the Kootenai have the carrying capacity to support 120 bears?

RESPONSE: The concept of carrying capacity is a theoretical one, especially difficult for the grizzly, and has not been adequately determined for any species. If the "Kootenai" refers to the CYE, then DEWP position is that this ecosystem can support this number of bears. As information from ongoing studies accumulates, this number may change and along with it the entire program is subject to periodic review. 
H-1. COMMENT: Why did DFWP reduce the number of annua 1 unreported deaths from 8 in the Preliminary EIS, to 7 in the Draft EIS.

RESPONSE: A rate of unreported mortality was estimated and applied to our original minimum population estimate of 387 in the preliminary draft of the EIS. Review of data in that draft resulted in a reduction of the population estimate to 356. Applying the rate for unreported mortalities to this new estimate reduced the number of deaths to 7 .

H-2. COMMENT: The estimate of unreported mortality is too low or inaccurately applied.

RESPONSE: DEWP obtained a 11 available information on this subject from state and federal agencies and from wild 1 ife agencies in Canada. DEWP has expanded the discussion on why the $4.0 \%$ rate should not be applied directly to the 1 ower population estimate. Briefly, research data show that subadu1t animals are most vulnerable to capture and human conflict. The sample of research bears from which we developed the rate, was derived primarily from the subadult segment of the population. DEWP does not believe that all bears in the NCDE with 4 designated wilderness areas and the protection they afford are equally vulnerable. Because our estimate was based on the most vulnerable animals it may be an overestimate.

H-3. COMMENT: Please do not present pooled mortality data in the EIS. This does not allow the reader to conduct separate analyses.

RESPONSE: DFWP combined several data sets to conduct specific tests on the mortality data. A primary purpose of data analysis is to synthesize data into a useful form for interpretation. DFWP does not believe that presentation of a 11 raw mortality data is necessary. If the mortality data were not pooled but presented as raw data it would be uninterpretable to the general public. Annual mortality data collected by DEWP (Greer 1967-1985) are available to the public upon request.

H-4. COMMENT: There is no substantiation that compensatory forces are at play in NCDE.

RESPONSE: Although there is some evidence that compensatory mortality and reproduction may be operative in the NCDE the evidence is speculative. Therefore, the reference to compensatory forces has been revised in the final EIS. 
H-5. COMMENT: Is human caused mortality compensatory or additive to natural mortality?

RESPONSE: The DFWP position on human-caused mortality, based on the data available, is that it is compensatory, the degree to which is unknown.

H-6. COMMENT: Is a population demonstrating a larger litter size increasing or merely responding to increased mortality?

RESPONSE: Populations have a wide range of responses to a wide array of mortality levels and environmental conditions. Litter size, in and of itself, can not indicate population status.

H-7. COMMENT: What is the definition of "overharvest" as used in the PDEIS?

RESPONSE: The DEWP defines overharvest as a 1 evel of harvest which results in a long term decline of the population in question.

H-8. COMMENT: Since few age composition data are available for grizzlies in NCDE, how reliable are harvest age composition data?

RESPONSE: Based on the literature review for the EIS, grizzly bear harvest age composition data, in and of itself, appears to be unreliable as an indicator of population status. This is primarily because data sets are small and often contradictory in their indications.

H-9. COMMENT: Can the NCDE grizzly population be compared with other populations in Yukon and British Columbia with confidence?

RESPONSE: The entire range of the grizzly bear as one species extends from Alaska to Montana. Comparisons between populations of the same species, including those in differing environmental conditions, is justifiable and widely practiced. The grizzly bear as a species is no exception. The comparisons are useful in determining differences and similarities.

H-10 COMMENT: Is DEWP suggesting that hunting pressure played no role in extirpation in historical ranges?

RESPONSE: Limited harvests of grizzly bears have not caused extirpation in historical ranges. The grizzly has been extirpated in a historical perspective through unlimited killing, federal predator elimination programs, and 
unrestrained 1 and development over much of his range. The fact that this EIS is even occurring is substantially attributable to the fact that Montana hunters intervened to stop the bear' elimination early in Montana history.

H-11 COMMENT: What effect does "mining" bears from selected areas have on grizzly bear populations?

RESPONSE: It is unclear what is meant by the term "mining." The effects of a substantial and localized mortality on the entire population would depend on the number, age, and sex of the mortalities and the size of the area considered. DFWP does not believe that current management unit subquotas will a $110 \mathrm{w}$ for a substantial mortality in $10 \mathrm{calized}$ areas. If problem areas develop, the management program can address them.

\section{WORST CASE ANALYSIS:}

I-1. COMMENT: The worst case analysis is too narrowly defined. It represents only the most extreme circumstances. There are other realistic scenarios that could be used in the worst case analysis.

RESPONSE: The parameters used in this analysis were taken from letters and comments received on the preliminary draft of the EIS. It was intended to represent the most extreme (thus worst case) scenario.

I-2. COMMENT: The modeling of the current management program using Harris' model should be run using a lower population estimate than 350-360.

RESPONSE: Based on DFWP's density estimate, this is the estimate of the minimum number of bears in the NCDE excluding Glacier National Park. Because this is the best estimate available, it is appropriate that this figure be used in the analysis. J. HABITAT MANAGEMENT:

J-1. COMMENT: How serious is DFWP about habitat preservation?

RESPONSE: DEWP has acquired 3 wildiffe management areas within grizzly bear habitat. These lands are managed for grizzlies and other wildlife species. A grizzly bear habitat mitigation program is currently being developed for Hungry Horse Reservoir within the NCDE. This proposed program calls for approximately 10,000 acres of habitat easement or acquisition primarily in the North and Middle Forks of the Flathead River. DFWP's mitigation program is currently under review by the Northwest Power Planning Council. If funded, 
preliminary work on the program could begin as early as July, 1986. The DFWP is supporting classification as wilderness some areas along the Rocky Mountain Front and elsewhere in the NCDE. However, it is apparent, as evidenced by the magnitude of impacts on grizzly bear. habitat, that DFWP efforts alone are not sufficient. Habitat protection needs public agency support as well as the support of private and public interests. The Rocky Mountain Front Management Guidelines deal with habitat protection.

J-2. COMMENT: Is this (EIS) an effort to turn Lincoln County into a wilderness area where no mining or logging is a11owed?

RESPONSE: DFWP's management direction within the management zone in the CYE is explained in the "Specific Department Goals for the Grizzly Bear" section of the EIS. The DFWP position is that a wilderness designation for the whole management area is not appropriate. As shown in the NCDE. the grizzly bear is capable of living in areas with certain level of timber harvest, oil and gas exploration, ski resorts and other human related activities. DFWP is managing to allow for delisting the grizzly in the CYE. Once accomplished, this will provide for more management flexibility to deal with these same activities in the CYE.

J-3. COMMENT: We are interested in how critical habitat will be designated and how these areas will be monitored.

RESPONSE: Critical grizzly bear habitat has not been delineated for either the NCDE or CYE. This is a federal government procedure not under the jurisdiction of DFWP.

\section{K. LEGAL CONTEXT:}

K-1 COMMENT: The discussion of extraordinary case in the EIS is legally deficient and therefore, hunting violates the Endangered Species Act (ESA). Use of sociological pressures as exemplifying extraordinary population pressure is not possible under the ESA and if it were it would only be appropriate around Choteau, MT.

RESPONSE: The use of sociological pressures as evidence for the extraordinary case has not been tested legally and therefore is not legally deficient. Assuming these pressures indicate the extraordinary case, a sport harvest or damange hunt does not violate the ESA.

The NCDE grizzly bear population is not a biologically isolated population. In fact, it is a continuation of the North American population which extends from Alaska to 
Montana and possibly to Wyoming. Further, population segments within the NCDE are not biologically isolated from each other. Thus bear/human conflicts whether in the vicinity of Choteau or elsewhere are representative of the population, not one area.

K-2. COMMENT: The Constitution of the State of Montana does not allow people to kill wild animals when the persons are engaged in the herding of sheep on the bears native range. The EIS incorrectly states the law on this point.

RESPONSE: First, the 1972 Constitution of Montana has no prohibition as described in this comment. Montana Code (873-130 MCA) provides for the killing of wild1ife species to protect human 1 ife and livestock. The Endangered Species Act is more stringent.

K-3. COMMENT: Has DEWP considered a lawsuit to force agencies to comply with best management practices in grizzly bear habitat?

RESPONSE: DFWP is not considering litigation. Our regional game managers have a good working relationship with the local land managers and cooperatively solve many "on theground" conflicts. The U.S. Fish and Wildiife Service has the legal mandate to assess the impacts of activities on the grizzly bear through the ESA section 7 consultation process.

K-4. COMMENT: Does the Federal Endangered Species Act preempt the States Endangered Species Act?

RESPONSE: No, the State's Endangered Species Act (87-5-101 to 87-5-112 MCA) is not preempted by the federal act, but is consistent with it.

K-5. COMMENT: How is it possible to ever get grizzly bear removed from the threatened 1 ist when DFWP indicates that it is nearly impossible to document exact numbers of grizzly bear in a system? Does this situation in itself mean that it would then in fact, be nearly improbable that the grizzly bear would ever be removed from the 1 ist?

RESPONSE: The DEWP position is that when the grizzly bear population in any ecosystem in Montana can be judged recovered based on the best data available, then that ecosystem population should be delisted.

K-6. COMMENT: DFWP has not shown adequate consideration of public involvement. Lack of notification of documents, insufficient time to study and research documents, and 1 ack 
of time for hearings. This does not meet the requirements of the National Wildife Protection Act.

RESPONSE: It is not clear what is referred to by the "National Wildife Protection Act", however, if this refers to the National Environmental Protection Act (NEPA) the E.IS was not prepared under this act. It was prepared under the the Montana Environmental Protection Act (MEPA) and meets a11 of the public participation requirements of this act. 
$\checkmark$

e

0 

6

6

- 